\title{
Radiation-Enhanced Anion Transport in Hematite
}

Kayla H. Yano $t^{1 *}$, Aaron A. Kohnert $\dagger^{2 *}$, Amitava Banerjee ${ }^{2}$, Danny J. Edwards ${ }^{1}$, Edward F. Holby $^{4}$, Tiffany C. Kaspar ${ }^{3}$, Hyosim Kim², Timothy G. Lach ${ }^{\circ}$, Sandra D. Taylor ${ }^{3}$, Yongqiang Wang $^{2}$, Blas P. Uberuaga ${ }^{2}$, Daniel K. Schreiber ${ }^{1}$

${ }^{1}$ Energy \& Environment Directorate, Pacific Northwest National Laboratory, Richland, WA, 99354, USA

${ }^{2}$ Material Science and Technology Division, Los Alamos National Laboratory, Los Alamos, NM, 87545, USA

${ }^{3}$ Physical and Computational Sciences Directorate, Pacific Northwest National Laboratory, Richland, WA, 99354, USA

${ }^{4}$ Sigma Division, Los Alamos National Laboratory, Los Alamos, NM, 87545, USA

*Corresponding authors, with both authors contributing equally to the work

${ }^{\circ}$ Currently located at Materials Science and Technology Division, Oak Ridge National Laboratory, Oak Ridge, TN, 37830, USA

\section{Supplementary Information}

Additional characterization data is provided here. Figures S1-S5 are in-depth atom probe tomography (APT) data while S6 and S7 provide additional transmission electron microscopy (TEM) characterization. A representative mass spectrum for $\mathrm{Fe}_{2} \mathrm{O}_{3}(\mathrm{~S} 1)$ and representative spectra for the ${ }^{18} \mathrm{O}$ and ${ }^{16} \mathrm{O}$ peaks used to calculate the ${ }^{18} \mathrm{O}$ isotopic fractions (S2) are provided. Figure $\mathrm{S} 3$ compares the APT-measured $\mathrm{O}$ composition of reference crystals of $\mathrm{Fe}_{2} \mathrm{O}_{3}$ and $\mathrm{Fe}_{3} \mathrm{O}_{4}$ versus the measurements performed here on as-grown, irradiated, and annealed thin film specimens. Note that the irradiated sample appears in both the $\mathrm{Fe}_{2} \mathrm{O}_{3}$ and $\mathrm{Fe}_{3} \mathrm{O}_{4}$ plots as it contained isolated regions of both phases. APT measurements are well-known to exhibit O-deficient compositions for oxide in general, and $\mathrm{Fe}$ oxide in particular, and these data provide a further basis for the phase identifications assigned to the APT data. The APT-measured atomic concentrations, calculated using a 1D concentration profile along the Z-axis of a cylindrical region of interest perpendicular to the tracer layer, for each APT specimen are included in Figure S4. Figure S5 provides representative frequency distribution data for $\mathrm{Fe}_{2} \mathrm{O}_{3}$ and $\mathrm{Fe}_{3} \mathrm{O}_{4}$ used to scale the APT 
reconstructions. These frequency plots how the interplanar ( $\mathrm{O}$ bilayer) spacing of the Fe oxide along the [0001] direction. Additional TEM imaging includes Fresnel imaging of voids (S6) and darkfield imaging of the magnetite phase at the surface and substrate of the vacuum-annealed film (S7). 


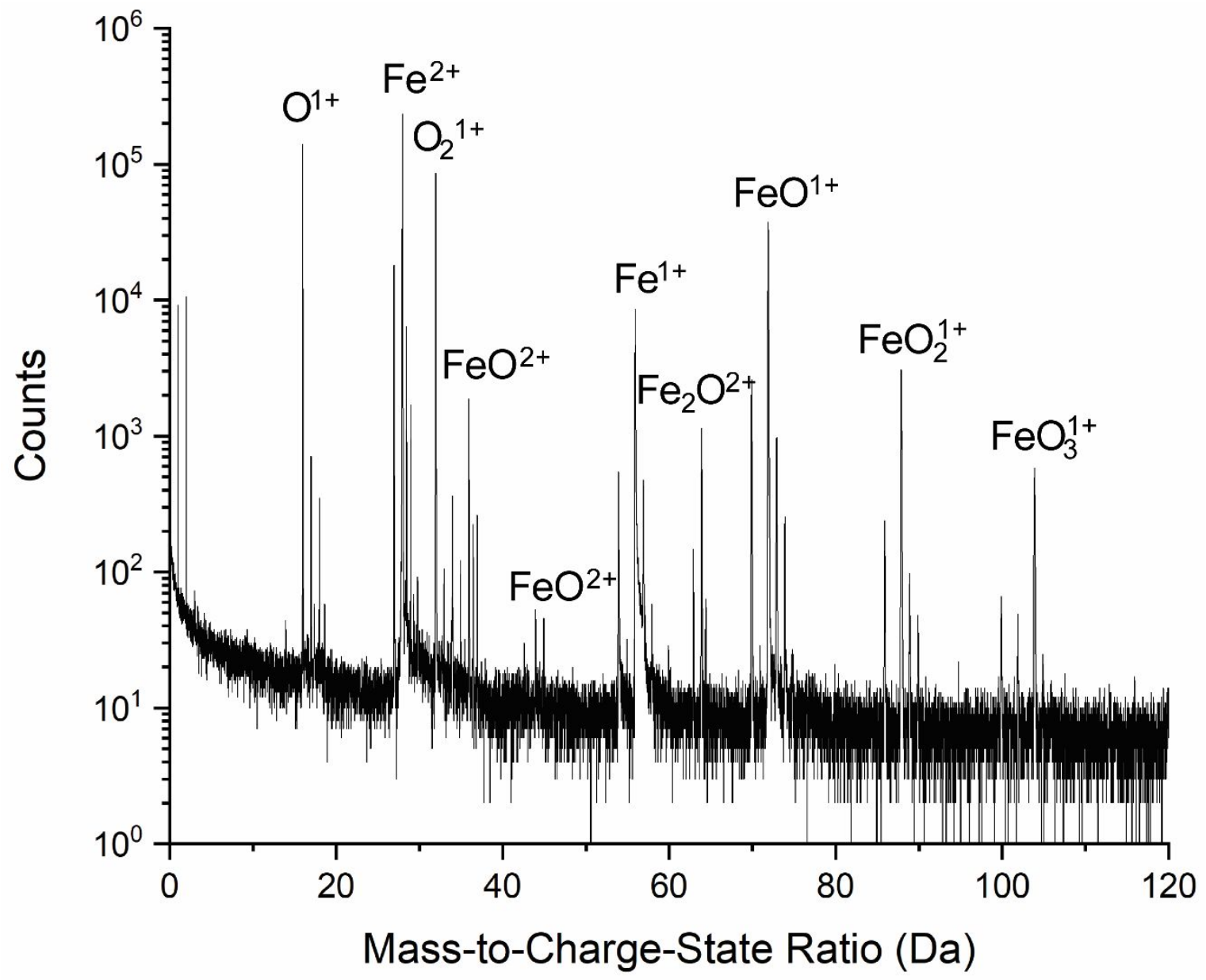

Figure S1. Mass spectra from APT analysis of $\mathbf{F e}_{2} \mathbf{O}_{3}$ film. Collected from the bulk $\mathrm{Fe}_{2} \mathrm{O}_{3}$, highlighting $\mathrm{Fe}, \mathrm{O}$, and $\mathrm{FeO}_{\mathrm{x}}$ species throughout the spectrum. 


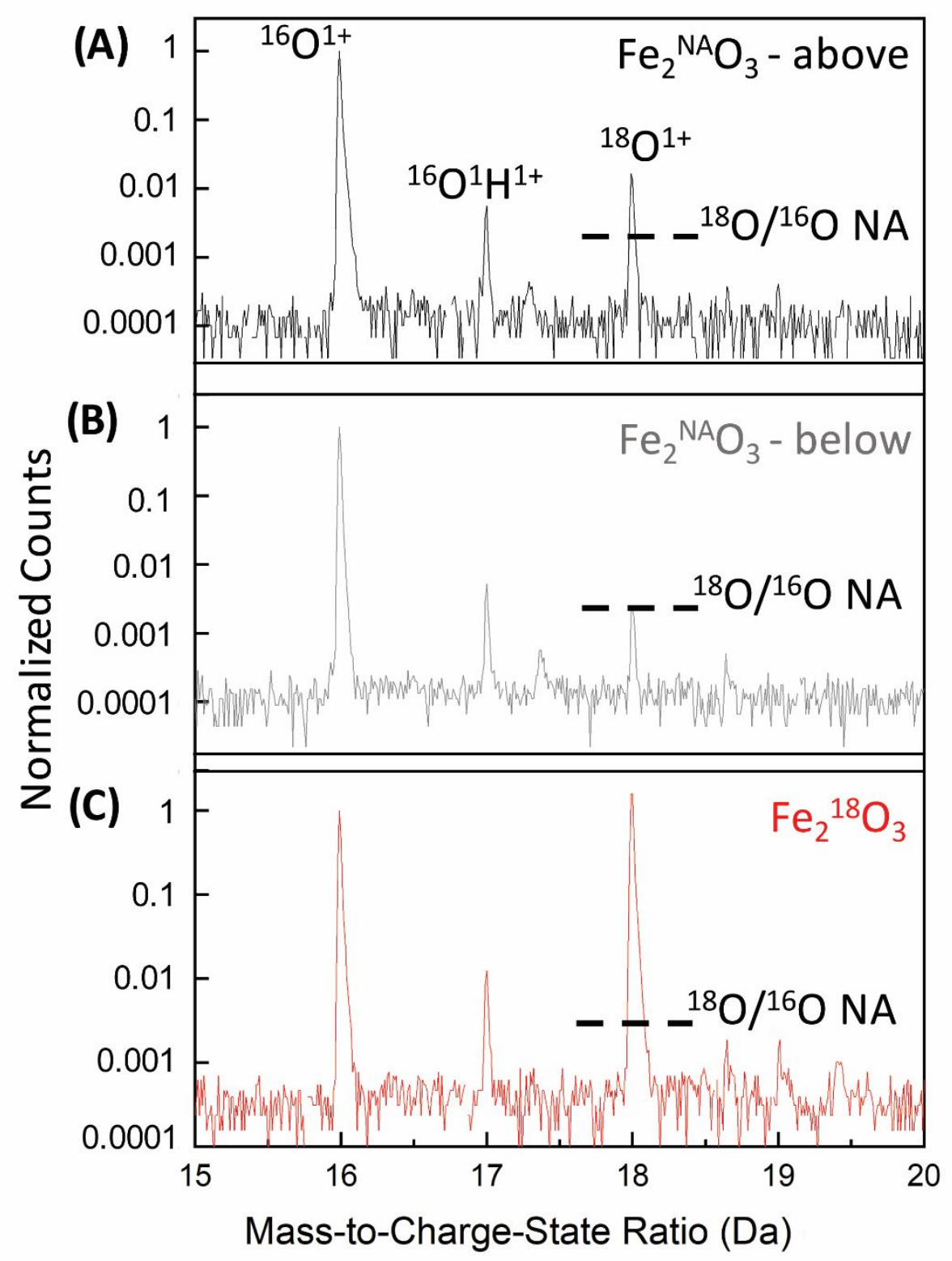

Figure S2. Mass spectra for dominant $\mathrm{O}$ ionic species across each $\mathbf{F e}_{2} \mathrm{O}_{3}$ layer; (A) $\mathrm{NA} \mathrm{Fe}_{2} \mathrm{O}_{3}$ above the ${ }^{18} \mathrm{O}$ layer, (B) the $\mathrm{Fe}_{2}{ }^{18} \mathrm{O}_{3}$ layer, and (C) $\mathrm{NA} \mathrm{Fe}_{2} \mathrm{O}_{3}$ below the ${ }^{18} \mathrm{O}$ layer. The y-axes counts are normalized to the ${ }^{16} \mathrm{O}^{1+}$ at $16 \mathrm{Da}$ and the dashed line represents ${ }^{18} \mathrm{O} /{ }^{16} \mathrm{O}$ expected at NA. 

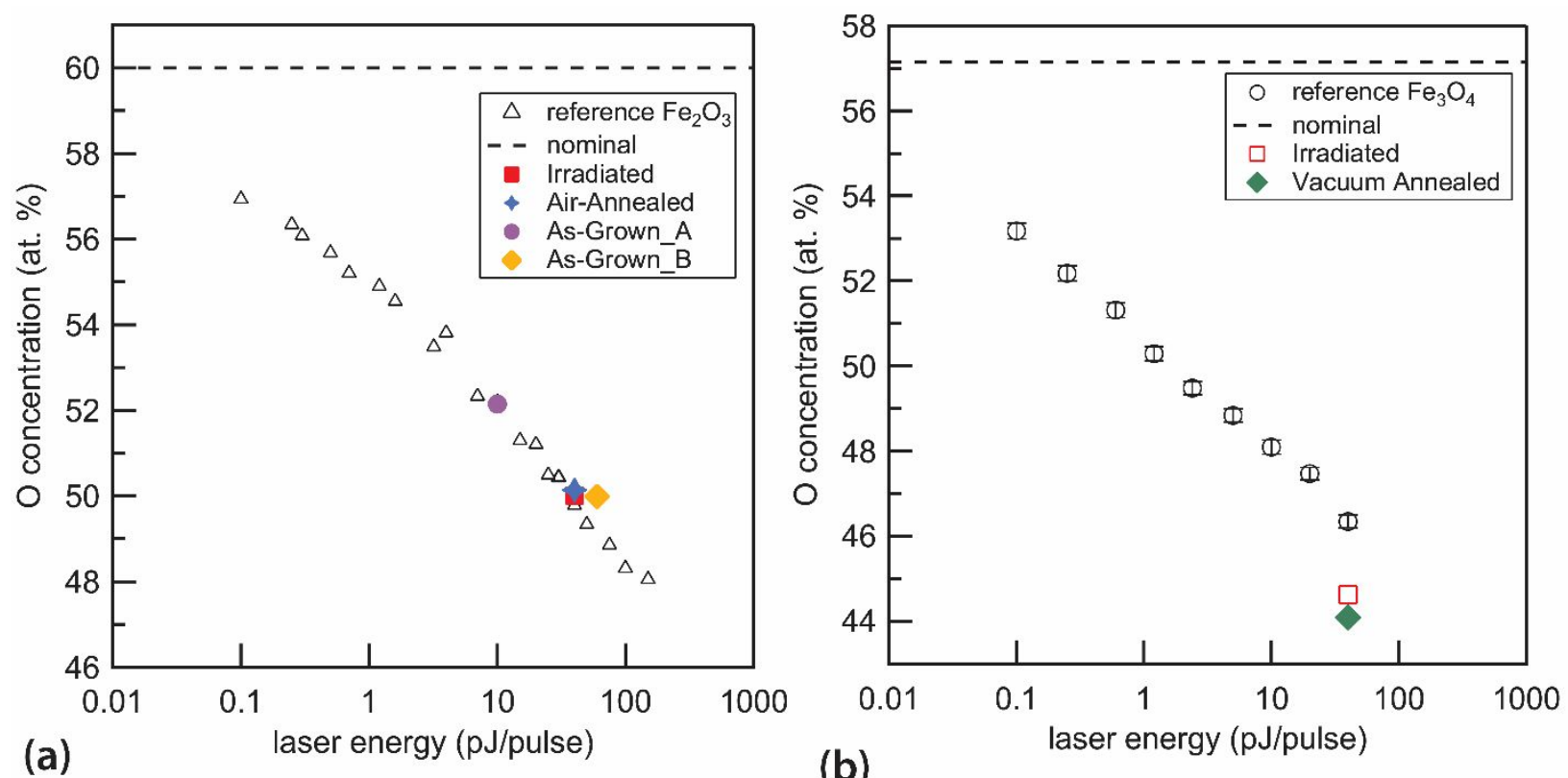

(b)

Figure S3. APT-measured oxygen compositions as a function of laser energy for reference single crystal oxides of: (a) $\mathrm{Fe}_{2} \mathrm{O}_{3}$ and (b) $\mathrm{Fe}_{3} \mathrm{O}_{4}$. Overlaid are experimental measurements of the films tested here after various treatments. The measured $\mathrm{O}$ composition is sensitive to the applied laser energy, which changes the field strength experienced by the APT specimen. The deviation away from the reference $\mathrm{Fe}_{3} \mathrm{O}_{4}$ data suggest the transformed $\mathrm{Fe}_{3} \mathrm{O}_{4}$ is $\mathrm{O}$ deficient but does not prove the deficiency on its own. 
(A) As-Grown, Stack A

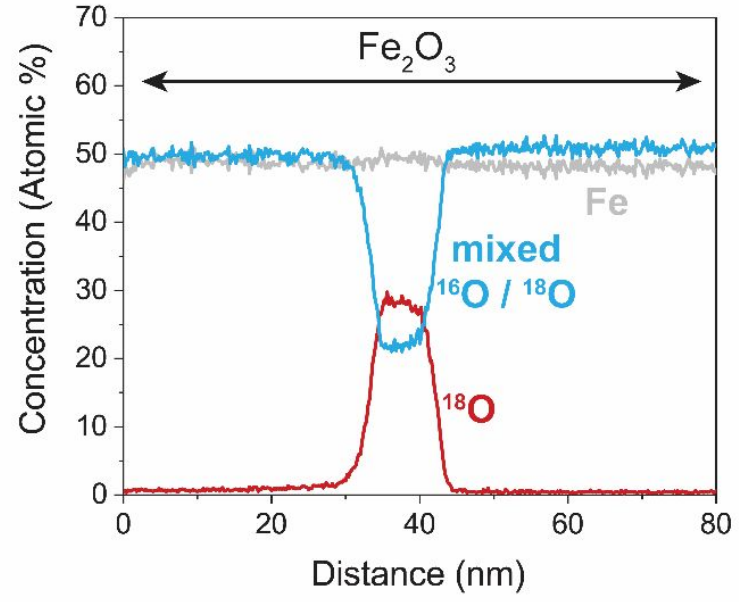

(C) Proton Irradiated, $0.1 \mathrm{dpa}, 450^{\circ} \mathrm{C}$, Stack $\mathrm{A}$

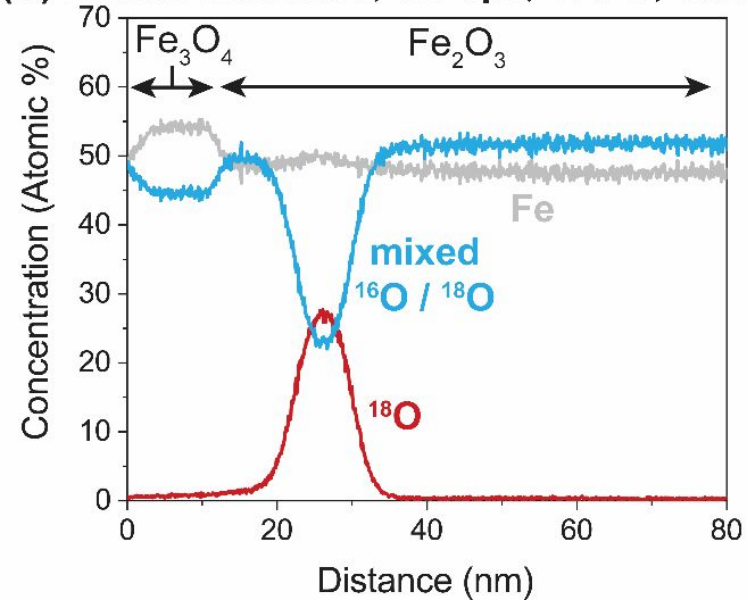

(B) Vacuum-Annealed, $450^{\circ} \mathrm{C}, 24 \mathrm{hrs}$, Stack $\mathrm{A}$

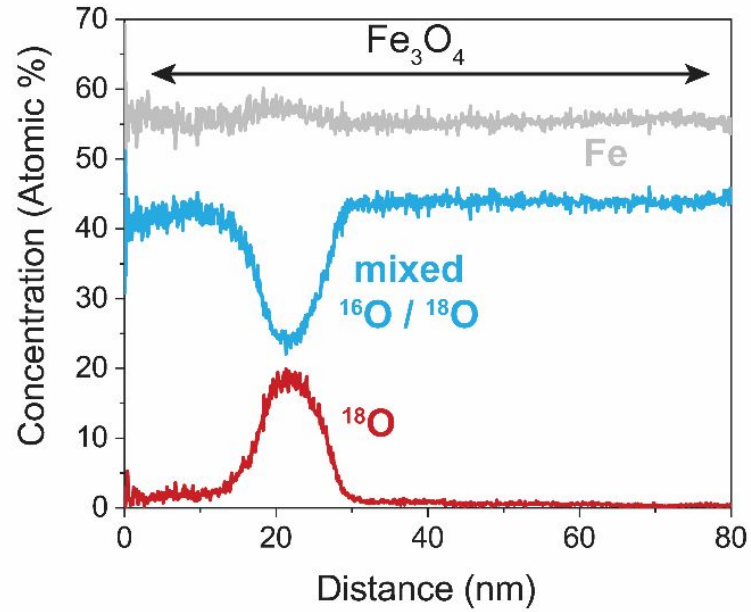

(D) Air-Annealed, $450^{\circ} \mathrm{C}, 72 \mathrm{hrs}$, Stack B

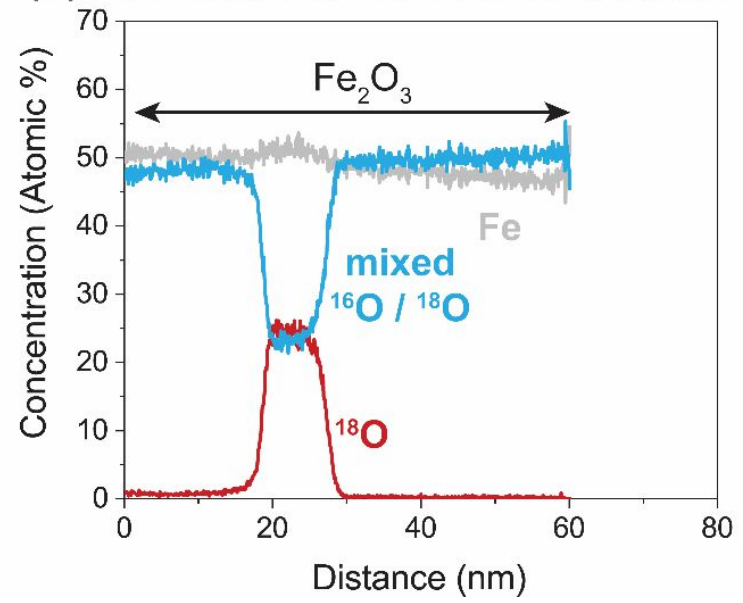

Figure S4. 1D atomic concentration profiles of: (A) as-grown, Stack A, (B) vacuum-annealed, Stack A, (C) proton irradiated, Stack A, and (D) air-annealed, Stack B. Deficiency in oxygen stoichiometry measurements in hematite have been reported previously in the literature ${ }^{1}$, consistent with our results here of ${ }^{16} \mathrm{O}$ measurements around 50 at.\%. Concentrations in vacuumannealed specimen (B) are different than those reported in A, C, and D panels due to a higher pulse energy used during that APT collection. 


\section{(A) $\mathrm{Fe}_{2} \mathrm{O}_{3}$ bilayer spacing-2.3 $\AA$}
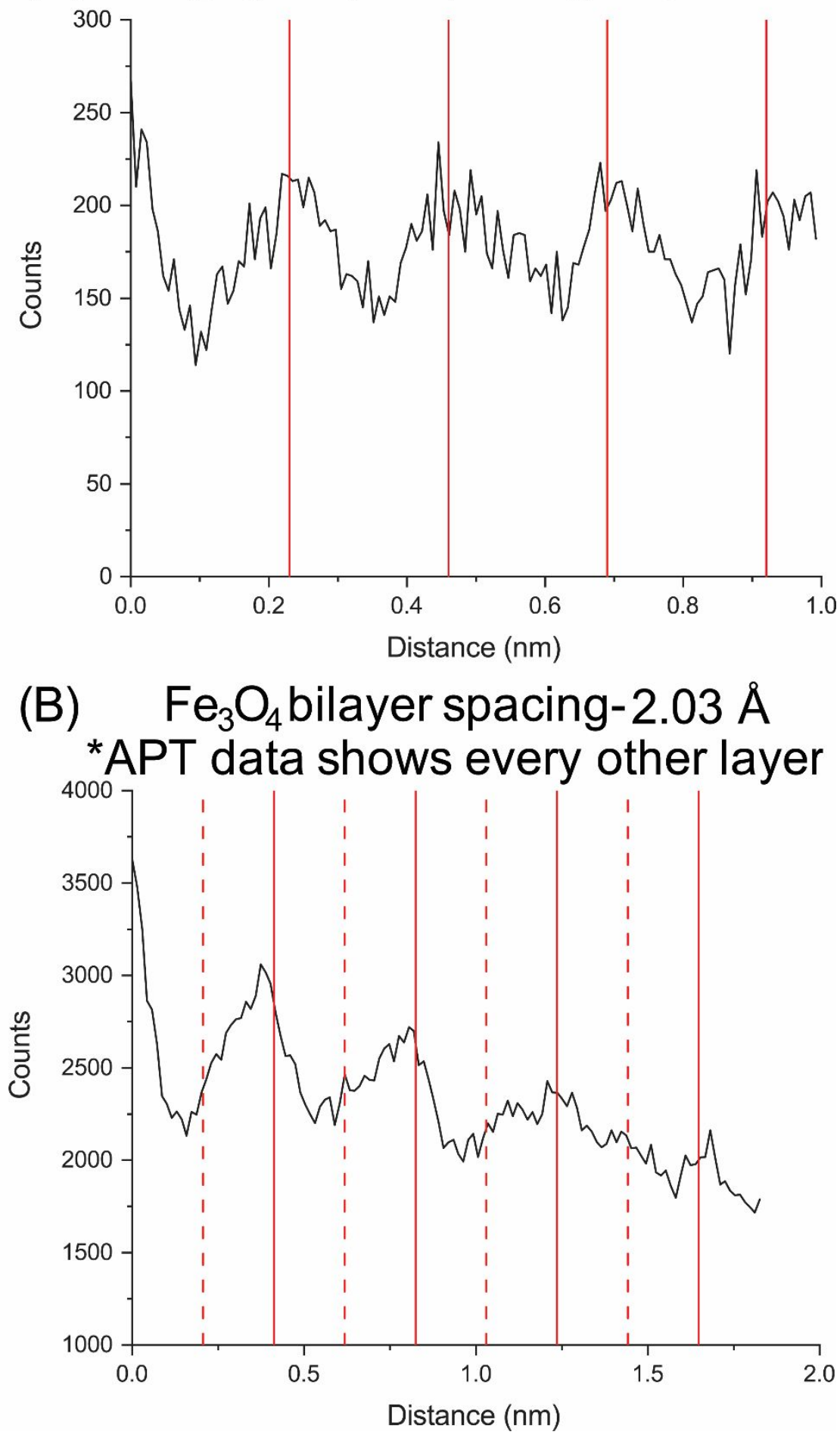

Figure S5. Representative frequency distributions for (A) hematite and (B) magnetite APT data. Using the frequency distribution function in IVAS, specimens could be scaled such that peak counts align with each bilayer. Bilayer spacing for $\mathrm{Fe}_{2} \mathrm{O}_{3}$ is $2.3 \AA$, while for $\mathrm{Fe}_{3} \mathrm{O}_{4}$ the spacing is $2.06 \AA$. Unlike in $\mathrm{Fe}_{2} \mathrm{O}_{3}$, every other layer appears in APT data for $\mathrm{Fe}_{3} \mathrm{O}_{4}$. 


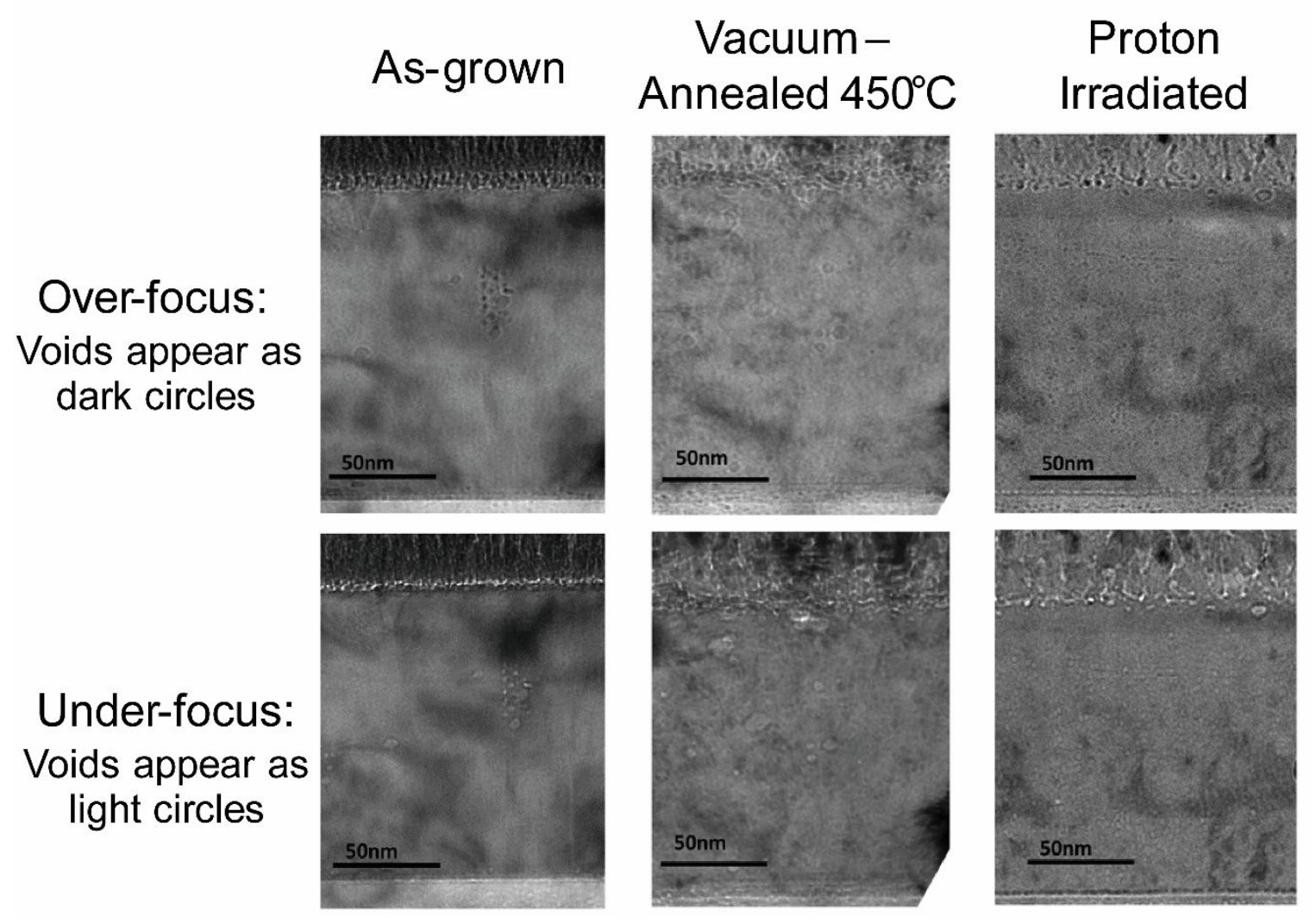

Figure S6. TEM under/over focus imaging of voids. Fresnel imaging is used to demonstrate voids present in as-grown, vacuum-annealed, and proton irradiated specimens. In overfocus conditions (upper row) voids have dark contrast. In underfocus conditions (lower row) voids have light contrast. 


\section{$\alpha-\mathrm{Fe}_{2} \mathrm{O}_{3}$ and $\mathrm{Cr}_{2} \mathrm{O}_{3}$}
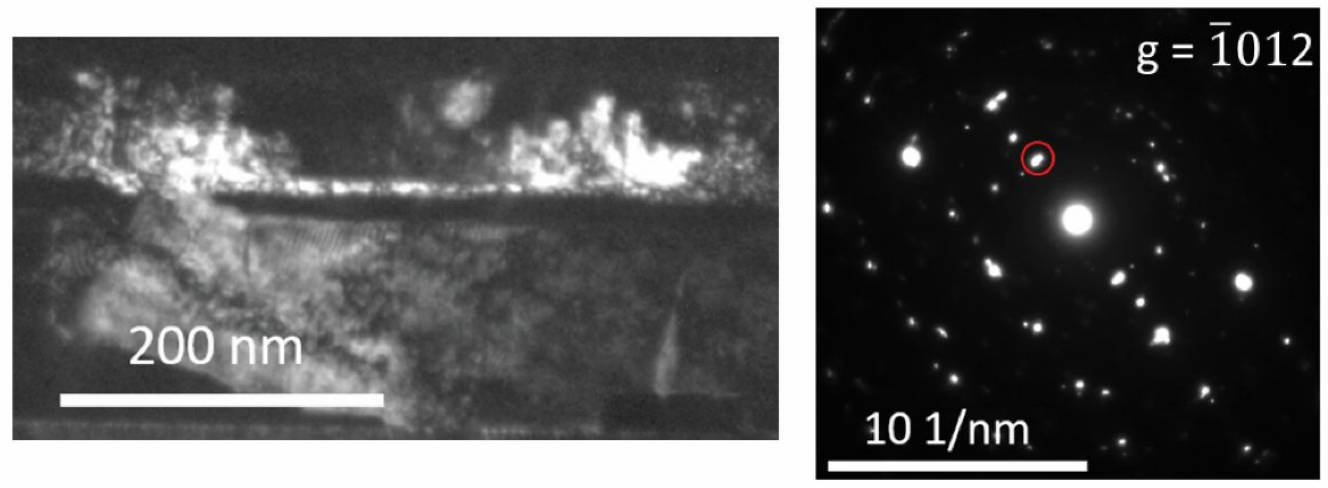

\section{$\mathrm{Fe}_{3} \mathrm{O}_{4}$}
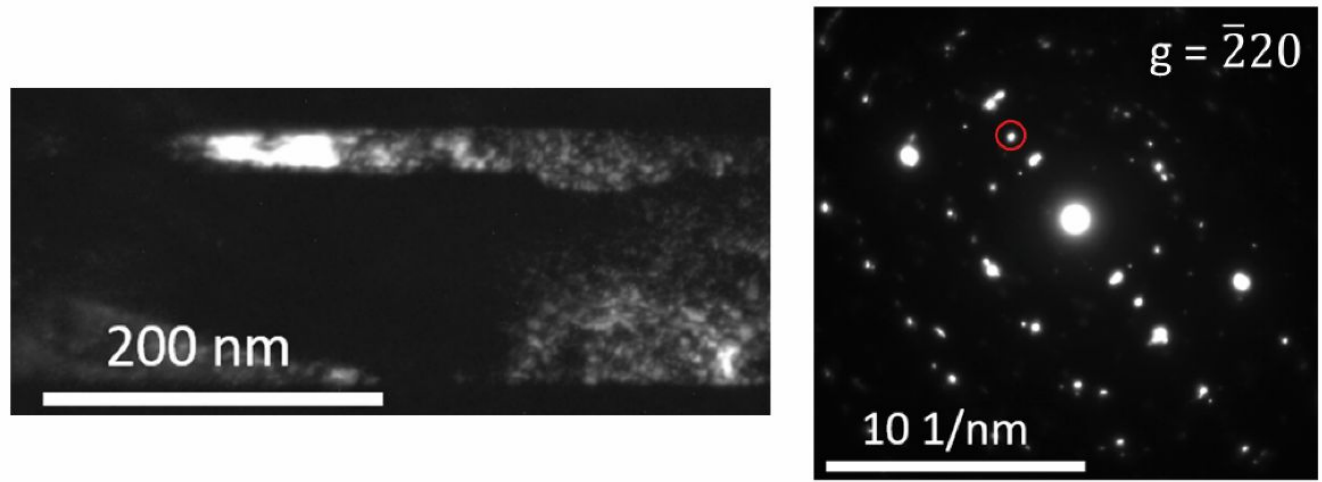

Figure S7. Dark field TEM with selected area electron diffraction (SAED) patterns of vacuum-annealed film. To highlight magnetite regions at surface and substrate dark field TEM imaging with SAED is used. (A) hematite and chromia (B) magnetite at upper surface of hematite film. Red circle in SAED patterns indicates reflection used for dark field imaging. 


\section{Reference}

(1) Bachhav, M.; Danoix, F.; Hannoyer, B.; Bassat, J. M.; Danoix, R. Investigation of O-18 Enriched Hematite ( $\alpha-\mathrm{Fe} 2 \mathrm{O} 3$ ) by Laser Assisted Atom Probe Tomography. Int. J. Mass Spectrom. 2013, 335, 57-60. https://doi.org/10.1016/j.ijms.2012.10.012. 